\title{
Oral Lesions In Covid 19 Positive Patients
}

\author{
Vural Fidan ${ }^{1}$, Handan Koyuncu ${ }^{2}$ and Okan Akin ${ }^{2}$ \\ ${ }^{1}$ Eskisehir Devlet Hastanesi \\ ${ }^{2}$ Affiliation not available
}

December 15, 2020

\begin{abstract}
Purpose: Since the beginning of the Covid 19 outbreak, many signs of the disease have been identified. It is known that Covid 19 uses the mouth area as an entrance to the respiratory tract. As with all diseases, early diagnosis and treatment is effective in the course of the disease in Covid 19. We aimed to identify the oral lesions of Covid 19 for detecting disease at early stages. Methods: Seventy-four patients whom detected Covid 19 in their nasopharyngeal swab were included in this study. Results: Fifty-eight of seventy-four patients had oral lesions. Aphthous-like ulcer was the most common oral lesion (n: 27). Respectively, other findings were erythema (n: 19) and lichen planus (n:12). The most common location of lesions was tongue (n: 23). Respectively, other lesion areas were buccal mucosa (n: 20), gingiva (n:11) and palate (n:4). Conclusion: In the study, more than half of Covid 19 patients had oral lesions. Therefore, oral evaluation is important in early diagnosis in cases whom suspected Covid 19.
\end{abstract}

\section{Hosted file}

Oral Lesions Covid 19 Positive Patients.pdf available at https://authorea.com/users/382957/ articles/498831-oral-lesions-in-covid-19-positive-patients

\section{Hosted file}

tables.pdf available at https://authorea.com/users/382957/articles/498831-oral-lesions-incovid-19-positive-patients 